\title{
Recomendações de Acessibilidade para a Equipe de um Software Livre Educacional
}

\author{
Flávia L. Arantes ${ }^{1}$, Davidson L. D. Piazza ${ }^{1}$, André C. da Silva ${ }^{1,2}$ \\ ${ }^{1}$ Núcleo de Informática Aplicada à Educação (NIED) - Universidade Estadual de \\ Campinas (UNICAMP) \\ Rua Seis de Agosto, 50 - Cidade Universitária - Campinas - SP - Brazil \\ ${ }^{2}$ Instituto Federal de São Paulo (IFSP) - Campus Hortolândia \\ Av. Thereza Ana Cecon Breda, s/n, Vila São Pedro - Hortolândia - SP - Brazil \\ farantes@unicamp.br, davidsonlisboa@hotmail.com, \\ andre.constantinodifsp.edu.br
}

\begin{abstract}
In this research, we propose to educate the development team of an $A V A$ for the importance of accessibility requirements. We are going to show accessibility recommendations and how to implement them in an AVA which is still in prototyping phase.
\end{abstract}

Resumo. Nesta pesquisa, procuramos conscientizar a equipe de desenvolvimento de um AVA para a importância dos requisitos de acessibilidade. Para tanto, propomos mostrar as recomendações de acessibilidade e como implementá-las no AVA ainda em sua fase de prototipação.

\section{Introdução}

Promover a acessibilidade e a inclusão digital consiste em um passo importante ao exercício da cidadania. Escolas, universidades e demais espaços educacionais devem dar acesso a recursos de informática e tirar proveito de suas possibilidades no desenvolvimento de seus estudantes [Melo, 2014].

Aos profisssionais da computação e da educação é indispensável compreender o que significa promover acessibilidade, cabendo a esses profissionais contribuir para minimizar as barreiras encontradas por pessoas com necessidades especiais no uso de tecnologias [Melo, 2014].

Os Ambientes Virtuais de Aprendizagem (AVAs) são uma solução importante para o ensino de uma forma geral, e têm o potencial de alcançar uma grande quantidade de pessoas. Eles são desenvolvidos com a finalidade de que seus participantes interajam através da tecnologia, contornando as barreiras impostas pela distância, para realizarem atividades educacionais nas modalidades presencial, semipresencial e a distância. Assim, são compostos por ferramentas que possibilitam a disponibilização de materiais, a comunicação síncrona ou assíncrona dos envolvidos, a construção de conteúdo e a gerência dos cursos disponibilizados aos estudantes [Silva et al., 2011].

O público de usuários de um AVA é muito amplo, diferindo em grau de conhecimento, classe social e faixa etária sem excluir pessoas com limitações físicas ou cognitivas. E para que esses usuários possam realizar as atividades de ensino e 
VI Congresso Brasileiro de Informática na Educação (CBIE 2017)

Anais do XXVIII Simpósio Brasileiro de Informática na Educação (SBIE 2017)

aprendizagem, é necessário que a interface do software não imponha barreiras para todo o público-alvo. Portanto a acessibilidade é um atributo chave desse tipo de software [Silva et al., 2011].

Nesta pesquisa, procuraremos conscientizar a equipe de desenvolvimento de um AVA para a importância de considerar requisitos de acessibilidade na construção do ambiente. O AVA escolhido é o TelEduc 5, que está atualmente na fase de levantamento de requisitos e prototipação de interfaces.

O objetivo deste trabalho é propor recomendações de acessibilidade para a equipe de desenvolvimento do software livre TelEduc. Pretendemos analisar os tipos de interfaces que estão em desenvolvimento, identificar lacunas de acessibilidade e criar recomendações para que a equipe possa desenvolver o ambiente já com os recursos de acessibilidade corretos.

Além de informar e conscientizar a equipe sobre a importância do tema, temos o desafio de lidar com desenvolvedores de uma equipe de software livre, que conta com a colaboração de desenvolvedores geograficamente distribuídos, os quais têm em mãos a liberdade de modificar e (re)utilizar o código fonte dos softwares sem custo.

A equipe de desenvolvedores do TelEduc é formada principalmente por estagiários e bolsistas, alunos de graduação de computação e áreas afins, que não possuem conhecimento sobre a construção de software considerando recursos de acessibilidade. A maior parte da equipe é centralizada, mas alguns desenvolvedores se encontram distribuídos, o que introduz a esta pesquisa o desafio de lidar com colaboradores geograficamente distantes.

\section{Metodologia}

A metodologia que utilizaremos para alcançar o objetivo deste trabalho está relacionada à realização das seguintes atividades:

a) Aplicação do WCAG 2.0 (W3C, 2008) ao TelEduc 5. Nesta etapa, cada critério de sucesso da recomendação WCAG 2.0 será analisada com relação a sua aplicação no TelEduc 5. Para cada critério, será feita uma descrição e uma justificativa para sua aplicação ou não no TelEduc.

b) Uma vez que os critérios de sucesso aplicáveis ao TelEduc forem identificados, será elaborado um documento com cada critério aplicável, o que fazer para implementar o critério e exemplos práticos de como fazer.

c) $\mathrm{O}$ documento produzido na etapa $\mathrm{b}$ ), servirá de subsídio para a elaboração de uma série de recomendações de acessibilidade para a equipe do TelEduc.

d) Os documentos produzidos em b) e c) servirão como conteúdo para a criação de um curso a distância, que será ministrado para a equipe de desenvolvimento, utilizado a própria plataforma TelEduc para hospedagem do curso. No curso, procuraremos conscientizar a equipe sobre a importância da acessibilidade em ambientes de $\mathrm{EaD}$, mostrar as recomendações de acessibilidade aplicadas ao TelEduc e mostrar como implementar as recomendações.

e) Por fim, pretendemos realizar testes de acessibilidade das interfaces do TelEduc produzidas antes e depois do curso para verificar as mudanças nas práticas de programação da equipe, advindas das aplicações das recomendações e práticas 
VI Congresso Brasileiro de Informática na Educação (CBIE 2017)

Anais do XXVIII Simpósio Brasileiro de Informática na Educação (SBIE 2017)

ministradas no curso. Para os testes de acessibilidade, será utilizada a ferramenta daSilva ${ }^{1}$, pois é amplamente utilizada e está de acordo com o WCAG 2.0.

\section{Resultados Parciais}

A fase a) descrita na metodologia foi finalizada e os resultados podem ser acessados em Piazza e Arantes (2017), onde o leitor encontrará dados como os mostrados na Tabela 1. A fase b) está em andamento e contará com dados similares aos da Tabela 2.

Tabela 1 - Critérios de sucesso do WCAG 2.0 aplicados ao TelEduc 5.

\begin{tabular}{|l|l|l|l|l|}
\hline $\begin{array}{l}\text { Critério de } \\
\text { Sucesso }\end{array}$ & Descrição & Nível & $\begin{array}{l}\text { Aplicação no } \\
\text { TelEduc 5 }\end{array}$ & Justificativa \\
\hline 1.1 .1 & $\begin{array}{l}\text { Conteúdo não textual exibido ao } \\
\text { usuário tem uma alternativa } \\
\text { textual que serve a um propósito } \\
\text { equivalente. }\end{array}$ & $\begin{array}{l}\text { Muito aplicável, } \\
\text { principalmente } \\
\text { para imagens. }\end{array}$ & $\begin{array}{l}\text { O TelEduc 5 usará em sua } \\
\text { interface imagens e ícones } \\
\text { que serão importantes para } \\
\text { o uso do ambiente. }\end{array}$ \\
\hline
\end{tabular}

Tabela 2 - Como implementar os critérios de sucesso.

\begin{tabular}{|l|l|l|}
\hline Critério de Sucesso & O que fazer & Como fazer \\
\hline 1.1 .1 & $\begin{array}{l}\text { Usar o atributo alt nos } \\
\text { elementos img do HTML. }\end{array}$ & $\begin{array}{l}\text { <img src="editIcon.gif" alt="Editar } \\
\text { atividade" / }\end{array}$ \\
\hline
\end{tabular}

\section{Direcionamentos Futuros}

O TelEduc 5 encontra-se em fase de modelagem e protótipos de interface, momento bastante favorável para a aplicação de uma metodologia como a descrita na seção 2 deste artigo. Esperamos com este trabalho, informar e conscientizar a equipe de desenvolvimento sobre a importância do suporte computacional para um ensino mais inclusivo e ter, como consequência, um AVA que trás as boas práticas da inclusão desde a sua concepção.

\section{Agradecimento}

Agradecemos ao apoio do CNPq por meio do projeto no 462478/2014-9.

\section{Referências}

Melo, A. M. (2014) “Acessibilidade e Inclusão Digital em Contexto Educacional”, In: 3o Congresso Brasileiro de Informática na Educação (CBIE), 3a Jornada de Atualização em Informática na Educação (JAIE). Dourados, MS, Novembro de 2014. pp. 1-42.

Piazza, D. L. D; Arantes, F. L. (2017) "Estudo das Diretrizes de Acessibilidade do WCAG 2.0 Aplicadas ao TelEduc 5". Relatórios Técnicos do NIED, n. 1 (2017). Disponível em: http://www.nied.unicamp.br/?q=rt. Acesso em 08/08/2017.

Silva, A. C.; Vargas, A.; Letízio, C.; Rocha, H. V.; Caceffo, R. (2011) "Avaliação da Usabilidade e da Acessibilidade do Ambiente Virtual de Aprendizagem TelEduc: levando o "aprender" a todos". In: IHC+CLIHC 2011, Porto de Galinhas - PE. pp. 1-10.

W3C Recommendation (2008). "Web Content Accessibility Guidelines (WCAG) 2.0". Disponível em https:/www.w3.org/TR/2008/REC-WCAG20-20081211/. Versão em Português em: https://www.w3.org/Translations/WCAG20-pt-br/. Acesso em 19/05/2017.

\footnotetext{
${ }^{1}$ http://www.dasilva.org.br/. Acesso em: 19/05/2017
} 